\title{
Von der Stadt zum Amt: Zur Genese württembergischer Herrschafts- und Verwaltungsstrukturen*
}

\author{
Von Peter Rückert
}

\section{Einführung}

Im zeitlichen und räumlichen Anschluss an die vorausgegangenen Beiträge ${ }^{1}$, soll im Folgenden der historische Fokus um das Land am mittleren Neckar geographisch etwas geöffnet und inhaltlich verdichtet werden: Die räumliche Durchdringung von Herrschaft, hier der Grafen von Württemberg, soll für das spätere Mittelalter verfolgt und analysiert werden. Wir befinden uns damit in der anhaltenden Fachdiskussion um Territorialisierungsprozesse, welche die Geschichtsschreibung des deutschen Spätmittelalters noch immer dominieren ${ }^{2}$.

Die Grafschaft Württemberg und hier zumal ihr Kernbereich um den mittleren Neckar bieten sich dafür aus mehreren Gründen an: Zum einen liegen die Schriftquellen gut aufbereitet vor, woraus ein gediegener Forschungsstand erwachsen ist, der gerade in jüngerer Zeit auch einige ausgereifte herrschaftsgeschichtliche Synthesen, vor allem von Dieter Mertens ${ }^{3}$ und Sönke Lorenz ${ }^{4}$, erfahren hat. Zum an-

" Dem Beitrag liegt der Vortrag zugrunde, der auf der Jahrestagung der Kommission für geschichtliche Landeskunde in Baden-Württemberg am 29. 6. 2012 in Marbach gehalten wurde. Der Vortragsstil wurde beibehalten, der Text um den wissenschaftlichen Apparat ergänzt.

${ }^{1}$ Siehe die Beiträge von Thomas Zotz, Heinz Krieg und Sönke Lorenz in diesem Band.

${ }^{2}$ Verwiesen sei an dieser Stelle nur auf die noch immer grundlegenden Arbeiten von Peter Moraw, vor allem: Die Entfaltung der deutschen Territorien im 14. und 15. Jahrhundert. In: Aus landesherrlichen Kanzleien im Spätmittelalter. Referate zum VI. Internationalen Kongreß für Diplomatik, München 1983. Teilband 1. Hg. von Gabriel Silagi (Münchener Beiträge zur Mediävistik und Renaissance-Forschung 35). München 1984. S.61-108, wieder abgedruckt in: Peter Moraw: Über König und Reich. Aufsätze zur deutschen Verfassungsgeschichte des späten Mittelalters. Hg. von Rainer Christoph Schwinges. Sigmaringen 1995. S. 89-126; hier vor allem S. $118 \mathrm{ff}$.

${ }^{3}$ Dieter Mertens: Württemberg. In: Handbuch der baden-württembergischen Geschichte. Bd.2: Die Territorien im Alten Reich. Hg. von Meinrad Schaab/Hansmartin Schwarzmaier. Stuttgart 1995. S. 1-163.

${ }^{4}$ Sönke Lorenz: Die Herrschaft Württemberg im Mittelalter: Von der Stammburg zur Residenz. In: Der württembergische Hof im 15. Jahrhundert. Beiträge einer Vortragsreihe 
deren haben gerade neue stadt- und verwaltungsgeschichtliche Erkenntnisse, oft auch punktuell geboten von Seiten der Stadtarchäologie, in breiterem, methodischen Zugriff angeregt von Seiten der boomenden Hof- und Residenzenforschung $^{5}$, auch neue sozialgeschichtliche Fragestellungen aufgeworfen, denen im Folgenden zu begegnen ist: Wir bewegen uns dabei in dem Zeitabschnitt zwischen dem Ende der Stauferherrschaft im späten 13. Jahrhundert, mithin dem Ansatz zur Formierung des württembergischen Territoriums, und dessen Teilung um die Mitte des 15. Jahrhunderts, als die ausgereifte Territorialstruktur der Grafschaft erstmals sichtbar wird.

Das wissenschaftliche Instrumentarium für unsere Untersuchung stellen neben der quellenkritisch zu hinterfragenden zeitgenössischen Terminologie, gerade in Hinblick auf räumliche Strukturen und herrschaftliche Amtsträger, die überlieferungsgeschichtlich determinierten Vergleiche dar: Ausgehend vom Raum am mittleren Neckar sollen Einzelbeispiele von Verwaltungseinheiten, späteren Ämtern, ihre Genese nachvollziehen lassen und im Vergleich zu allgemeiner gültigen, strukturgeschichtlich relevanten Erkenntnissen führen. Dabei sind die aktuellen Kenntnisse von Mittelalterarchäologie, Stadt- und Verwaltungsgeschichte selbstredend mit einzubeziehen.

Auszugehen ist freilich zunächst von den Erkenntnissen der modernen Stadtgeschichtsforschung ${ }^{6}$ : Pointiert formuliert stand am Anfang eines jeden Amtes, zu-

des Arbeitskreises für Landes- und Ortsgeschichte, Stuttgart. Hg. von Peter Rückert (VKgL B 167). Stuttgart 2006. S. 9-52; - Ders., Vom herrschaftlichen Rat zu den Landständen in Württemberg. Die Entwicklung vom 13. bis zum 16. Jahrhundert. In: Auf dem Weg zur politischen Partizipation? Landstände und Herrschaft im deutschen Südwesten. Hg. von Sönke Lorenz/Peter Rückert (VKgL B 182). Stuttgart 2010. S.1-28. Vgl. daneben auch Peter Rückert, Dynastie - Hof - Territorium. Zur Herrschaftsbildung der Grafen von Württemberg im späteren Mittelalter. In: Das Land am mittleren Neckar zwischen Baden und Württemberg. Hg. von Hansmartin Schwarzmaier/Peter Rückert (Oberrheinische Studien 24). Ostfildern 2005. S. 189-212.

${ }^{5}$ Grundlegend dazu: Höfe und Residenzen im spätmittelalterlichen Reich. Ein dynastisch-topographisches Handbuch. 2 Teilbände. Hg. von Werner Paravicini u.a. (Residenzenforschung 15.1), Ostfildern 2003, darin besonders Sönke Lorenz: Württemberg, Bd.1, S. 225-234, sowie ders.: Württemberg (mit Mömpelgard), Bd.2, S. 909-915, sowie Oliver Ange: Stuttgart, Bd.2, S. 568-571, Sönke Lorenz: Tübingen, Bd. 2, S. 592-595, Roland Deigendesch: Urach, Bd.2, S.600-604. - Vgl. für Württemberg zuletzt die Beiträge in: Der württembergische Hof im 15. Jahrhundert (wie Anm. 4); - Christian Hesse: Amtsträger der Fürsten im spätmittelalterlichen Reich. Die Funktionseliten der lokalen Verwaltung in Bayern-Landshut, Hessen, Sachsen und Württemberg, 1350-1515 (Schriftenreihe der Historischen Kommission bei der bayerischen Akademie der Wissenschaften 70). Göttingen 2005; - Nina Kübnle: Zwischen Landesteilung und Wiedervereinigung: Die württembergischen Höfe Stuttgart und Urach (1442-1482). In: ZWLG 68 (2009) S. 103-139.

${ }^{6}$ Zum aktuellen Forschungsstand der Stadtgeschichts- und Urbanisierungsforschung vgl. zuletzt etwa die Beiträge in: Die Urbanisierung Europas von der Antike bis in die Moderne. Hg. von Gerhard Fouquet / Gabriel Zeilinger (Kieler Werkstücke E 7). Frankfurt u. a. 2009; - Thomas Zotz: Der Prozess der Urbanisierung und die Entwicklung der Stadt-Land-Beziehungen. In: Adel und Bauern in der Gesellschaft des Mittelalters. Internationales Kolloqui- 
mal in Württemberg, eine Stadt. Hier spricht man deshalb auch von „Amtsstädten“, die sich von den wenigen anderen Städten des Territoriums zunächst dadurch unterscheiden, dass von hier aus hoheitliche Funktionen für ihren Amtsbezirk wahrgenommen werden ${ }^{7}$. Diese Amtsstädte fungieren im ausgehenden Mittelalter als Zentren der herrschaftlichen Lokalverwaltung und stehen für einen flächendeckend organisierten Verwaltungsapparat, der den vorläufigen erfolgreichen Abschluss des württembergischen Territorialisierungsprozesses an der Wende zur Neuzeit bezeichnet.

Doch, wie ist es soweit gekommen? Wie haben wir uns die raumgreifende, herrschaftliche Entwicklung von der hochmittelalterlichen Stadt zum spätmittelalterlichen Amt vorzustellen? Denn eine von der Stadt- bzw. Territorialherrschaft dominierte Entwicklung muss es schon gewesen sein, die eine flächendeckende Herrschaft über Land und Leute zur Folge hat. Hierfür liegen bislang nur wenige, beispielhafte aufgearbeitete Einzelaspekte vor, die nun in einem zeitlichen Längsschnitt systematisch ergänzt und zu einem kontrastreicheren Bild verdichtet werden sollen.

Wir gehen dabei von den frühen Städten der Grafen von Württemberg aus, wie diese uns im späten 13. Jahrhundert entgegentreten, und fragen zunächst nach deren älteren herrschaftlichen Strukturen. Daran schließt sich die Frage nach ihrer Qualität als „zentrale Orte“ an: die sogenannte „Zentralitätstheorie“, die lange die

um zum 65. Geburtstag von Werner Rösener. Hg. von Carola Fey/Steffen Krieb (Studien und Texte zur Geistes- und Sozialgeschichte des Mittelalters 6). Korb 2012. S.65-78. - Für Württemberg vgl. die Überblicksdarstellung von Jürgen Sydow: Städte im deutschen Südwesten. Ihre Geschichte von der Römerzeit bis zur Gegenwart. Stuttgart u. a. 1987; daneben den Forschungsüberblick von Sönke Lorenz: Staufische Stadtgründungen im deutschen Südwesten. Aktuelle Aspekte, Tendenzen und Perspektiven in der Stadtgeschichtsforschung. In: Staufische Stadtgründungen am Oberrhein. Hg. von Eugen Reinhard/Peter Rückert (Oberrheinische Studien 15). Stuttgart 1998. S. 235-272; - Volker Trugenberger: „Ob den portten drey hirschhorn in gelbem veld“ - Die württembergische Amtsstadt im 15. und 16. Jahrhundert. In: Landesherrliche Städte in Südwestdeutschland. Hg. von Jürgen Treffeisen/Kurt Andermann (Oberrheinische Studien 12). Sigmaringen 1994. S.131-156, sowie zuletzt Oliver Auge/Nina Kühnle: Zwischen „Ehrbarkeit“ und Landesherrschaft. Städtische Entwicklung im spätmittelalterlichen Württemberg. In: ZWLG 71 (2012) 107-128. - Zu den Städten der Markgrafen von Baden im Mittelalter vgl. Rüdiger Stenzel: Die Städte der Markgrafen von Baden. In: Landesherrliche Städte in Südwestdeutschland. Hg. von Jürgen Treffeisen/Kurt Andermann (Oberrheinische Studien 12). Sigmaringen 1994. S. 89-130, sowie zuletzt den knappen Überblick bei Gerhard Fonquet: Die Städte der Markgrafen von Baden. In: Baden! 900 Jahre. Geschichten eines Landes. Hg. von Oliver Sänger. Karlsruhe 2012. S. 44 (mit Karte S. 45).

7 Grundlegend zum Themenkomplex um Stadt und Amt in Württemberg sind noch immer die Forschungen von Walter Grube: Vogteien, Ämter, Landkreise in Baden-Württemberg. Bd. 1: Geschichtliche Grundlagen. Stuttgart 1975;-Ders.: Stadt und Amt in Altwürttemberg. In: Stadt und Umland. Protokoll der X. Arbeitstagung des Arbeitskreises für südwestdeutsche Stadtgeschichtsforschung, Calw 12.-14.November 1971 (VKgL B 82). Stuttgart 1974. S. 20-28. 
Historische Geographie beschäftigt hat ${ }^{8}$ und in aktuellen Fragestellungen um Urbanisierung und Städtelandschaften wieder aufgenommen wird ${ }^{9}$, soll hier den Blick für die Profilierung dieser Städte schärfen. Die von den Quellen dokumentierten herrschaftlichen Maßnahmen und ihre Träger, die herrschaftlichen Funktionäre vor Ort, sind anschließend für das wachsende württembergische Territorium zumindest beispielhaft zu erfassen. Die Verschriftlichung der Verwaltung und deren von der Überlieferung gespiegelte Differenzierung sollen parallel dazu analysiert werden. Anhand unserer Einzelbeispiele ist mit der Genese der Amtsstruktur schließlich nach ihrer sozialen Gestalt und der Identifizierung der Amtsträger mit ihrer Herrschaft bzw. dem „Land Württemberg“ zu fragen.

\section{Die frühen Städte der Grafen von Württemberg}

Um die Mitte des 13. Jahrhunderts, als die Grafen von Württemberg in weiten Teilen das Erbe der Staufer antreten sollten, verfügten sie mit Leonberg, Waiblingen und Stuttgart zunächst nur über drei Städte. Schorndorf und Cannstatt kamen schnell dazu: bis zum Jahr 1400 wuchs ihre Zahl auf über 50, die dann bis zum Beginn des 16. Jahrhunderts noch auf über 60 Städte steigen sollte ${ }^{10}$.

Das Eigentümliche an der württembergischen Städtelandschaft ist bekanntlich, dass die Grafen selbst nur im Einzelfall als Stadtgründer auftreten, konkreter: Der aktuelle Forschungsstand bietet bislang nur eine einzige Stadt, Leonberg, welche die Grafen von Württemberg als solche angelegt haben, einige wenige andere Orte haben sie aus älteren Dörfern zu Städten ausgebaut bzw. deren mehr oder weniger weit gediehenen Stadtwerdungsprozess fördernd begleitet, wie bei Stuttgart, Waiblingen, Schorndorf oder Cannstatt ${ }^{11}$. Die ganz überwiegende Mehrzahl ihrer spätmittelalterlichen Städte haben die Württemberger von anderen Herrschaften übernommen. Die markanten Eckpunkte der territorialen Erweiterungen werden

${ }^{8}$ Vgl. dazu den aktuellen Überblick über den Forschungsstand der Historischen Geographie bei Rüdiger Glaser/Hans Gebhardt/Winfried Schenk: Geographie Deutschlands. Darmstadt 2007; v.a. S. 73.

9 Vgl. etwa Städtelandschaft / Réseau urbain / Urban Network. Städte im regionalen Kontext in Spätmittelalter und früher Neuzeit. Hg. von Holger Th. Gräf/Katrin Keller (Städteforschung A 62). Köln u. a. 2004; - Monika Escher/Frank G. Hirschmann: Die urbanen Zentren des hohen und späten Mittelalters. Vergleichende Untersuchungen zu Städten und Städtelandschaften im Westen des Reiches und in Ostfrankreich (Trierer Historische Forschungen 50). 3 Bde. Trier 2005; - Karlheinz Blaschke: Von der Kaufmannssiedlung zur Stadt. Beobachtungen über den Aufbruch im 12. Jahrhundert. In: Historische Zeitschrift 294 (2012) S. 653-686; dazu auch Auge/Kübnle (wie Anm. 6) S. 115.

10 Ange/Kühnle (wie Anm. 6) S. 122.

11 Zum älteren Forschungsstand vgl. Karl Weller/Arnold Weller: Württembergische Geschichte im südwestdeutschen Raum. Stuttgart ${ }^{9} 1981$; - Elmar Blessing: Beiwort zu Karte VI,2. Die territoriale Entwicklung von Württemberg bis 1796 einschließlich der linksrheinischen Besitzungen. In: HABW. Erläuterungen. Bd.1. S. 1-4. 
gesetzt mit dem Erwerb der Grafschaften Urach und Achalm (um 1254), der Herrschaft Teck bald darauf, der Ausdehnung nach Westen und Norden, in den Schwarzwald bzw. Zabergäu hinein, ebenfalls um 1300, und etwas später nach Süden, wo sie bis um 1400 auch das Erbe der Pfalzgrafen von Tübingen antreten sollten ${ }^{12}$.

Mit diesen territorialen Erweiterungen kamen auch deren herrschaftliche Zentralorte, Burgen und Städte, in den Besitz der Grafen und sollten anschließend unter württembergischer Herrschaft in das Territorium eingegliedert werden. Hier ist nach Mustern und Strategien zu fragen, die zu einer erfolgreichen, schließlich flächendeckenden Integration der neuen Herrschaftsteile führten.

Blicken wir aber zunächst kurz zurück: Um die Mitte des 13. Jahrhunderts wurde die Städtelandschaft am mittleren Neckar dominiert von einigen zentralen Orten, die sich durch ihre zentrale Verkehrslage, ihre wirtschaftliche und herrschaftliche Bedeutung aus ihrer Umgebung heraushoben ${ }^{13}$ : Neben den seit der Römerzeit bedeutenden Verkehrszentren Wimpfen und Cannstatt, sind es nun vor allem Esslingen und Heilbronn, die frühe städtische Qualität gewinnen und bald, jedenfalls im 12. Jahrhundert, als die beiden bedeutendsten wirtschaftlichen Zentren am mittleren Neckar anzusehen sind (Abb. 4). Daneben tauchen damals noch Marbach und Tübingen als Markt- und Münzorte auf, die wir später ebenso wie Cannstatt unter württembergischer Herrschaft wiederfinden werden ${ }^{14}$.

Im 12. und frühen 13. Jahrhundert sind die genannten Städte weitgehend im Besitz des Königtums, der Staufer. In Wimpfen hatten diese eine mächtige Pfalz errichtet, in Cannstatt tauchen neben den Staufern bald adelige Herren im Gefolge ihrer mächtigen Helfer, der Markgrafen von Baden und der Grafen von Württemberg, auf, welche offenbar bald auch unterschiedliche Herrschaftsrechte vor Ort vertreten ${ }^{15}$. Esslingen und Heilbronn sind als wirtschaftlich bedeutende „Stauferstädte" hinlänglich bekannt; weitreichende königliche Privilegien begleiten damals ihren Weg zur Autonomie der sogenannten „freien Reichsstädte“ im späteren Mittelalter. In Marbach finden wir die Markgrafen von Baden, in Tübingen die Pfalzgrafen von Tübingen als neue Stadtherren am Werk.

Die Grafen von Württemberg treten hier, wie erwähnt, erst mit dem Ende der Stauferherrschaft, um 1250, hinzu. Sönke Lorenz hat diese markante Situation des herrschaftlichen Übergangs von den Staufern auf die Württemberger als neuer dominanter Dynastie am mittleren Neckar bereits instruktiv vorgestellt ${ }^{16}$. Für unsere

${ }^{12}$ Vgl. den herrschaftsgeschichtlichen Überblick bei Lorenz, Die Herrschaft Württemberg (wie Anm. 4).

${ }^{13}$ Dazu ausführlicher Peter Rückert: Wirtschaft und Verkehr am mittleren Neckar im Hochmittelalter. In: Wirtschaft, Handel und Verkehr im Mittelalter. 1000 Jahre Markt- und Münzrecht in Marbach am Neckar. Hg. von Sönke Lorenz/Peter Rückert (Tübinger Bausteine zur Landesgeschichte 19). Ostfildern 2012. S. 53-75.

14 Ebd. S. 58.

15 Ebd. S. 66f. (mit weiterer Literatur).

16 Siehe den Beitrag von Sönke Lorenz in diesem Band. 
Fragestellung bleibt festzuhalten, dass diese neben der staufischen Stadt Markgröningen ${ }^{17}$ jetzt auch Schorndorf und Waiblingen aus staufischem Besitz übernehmen, die bald als württembergische Städte entgegentreten. Gleichzeitig ziehen die Grafen von Württemberg hier nach und nach in die zentralen markgräflich-badischen Positionen ein: vor allem nach Stuttgart, das sicher bereits städtische Qualität besa $\beta^{18}$, ebenso in das benachbarte Cannstatt, wo sie die staufischen und markgräflichen Herrschaftsrechte übernehmen und den Stadtwerdungsprozess weiter fördern ${ }^{19}$.

Versuchen wir, diese gängigen Aussagen für die genannten Fälle zu konkretisieren: Dass für die Urbanisierungsprozesse zunächst ein starker zeitgenössischer Bevölkerungszuwachs die demographischen Möglichkeiten bietet, dass wirtschaftliche und herrschaftlich-fortifikatorische Perspektiven gemeinhin als Anreize für die Welle der hochmittelalterlichen Stadtgründungen gelten, ist bekannt; ebenso ihr herrschaftliches Profil, das - vergleichbar mit dem Burgenbau - die neuen Städte als zeitgemäßes politisches Mittel zur Machtverdichtung und herrschaftlichen Repräsentation zunächst der Elite, des Königtums und der Reichsfürsten, kennzeichnet.

Im Falle von Leonberg sind wir über die Stadtgründung durch die „Sindelfinger Annalen“ zum Jahr 1248 unterrichtet: ... civitas Levinberch fundata fuit et inchoata novis aedificiis et muro a comite de Wirtinberch ... ${ }^{20}$. Dieser Graf von Württemberg wird mit Ulrich I. (†1265) identifiziert, der die Stadt unweit einer älteren, auf dem Endelberg über dem Glemstal gelegenen Burg, anlegen ließ und ihr deren Namen übertrug ${ }^{21}$ (Abb. 3).

Der Festungscharakter der neuen Stadt tritt noch immer deutlich hervor, burgartig passt sie sich ihrer Spornlage an; ein regelmäßiges Straßennetz in Gitterform steht für den Anlageplan ${ }^{22}$. Neben den genannten Häusern und der Stadtmauer wurden hier bald eine Kapelle und eine Stadtburg als Herrschaftssitz ausgebaut: Die alte Burg Löwenberg zerfiel, und auch die Bewohner des Nachbardorfes Dilgshausen sollten nach und nach in die neue Stadt übersiedeln und ihr Dorf auflassen.

17 Vgl. Lorenz, Die Herrschaft Württemberg (wie Anm. 4) S. 30.

18 Siehe dazu Oliver Auge: 775 Jahre „Stutkarcen“. Zu den Anfängen Stuttgarts im Zeithorizont des Früh- und Hochmittelalters. In: ZWLG 64 (2005) S. 11-22, sowie jetzt Hartmut Schäfer: Die Anfänge Stuttgarts. Vom Stutengarten bis zur württembergischen Residenz. Stuttgart 2012.

19 Vgl. Jürgen Hagel: Cannstatt und seine Geschichte. Tübingen 2002.

20 Zitat nach Lorenz, Die Herrschaft Württemberg (wie Anm. 4) S. 29. Hier finden sich auch weitere Ausführungen zu den „Sindelfinger Annalen“.

${ }^{21} \mathrm{Vgl}$. auch zum Folgenden: Leonberg. Eine altwürttembergische Stadt und ihre Gemeinden im Wandel der Geschichte. Hg. von Wilfried Setzler/Hansmartin Decker-Hauff u. a. Stuttgart [1992].

${ }^{22}$ Vgl. Das Land Baden-Württemberg. Eine amtliche Beschreibung nach Kreisen und Gemeinden. Hg. von der Landesarchivdirektion Baden-Württemberg. Bd.3. Stuttgart 1978. S. 112 . 
Allein die dortige Pfarrkirche bestand außerhalb der Stadtmauern bis in die Reformationszeit weiter. Leonberg steht somit für einen herrschaftsstrategisch motivierten Planungsakt des Württemberger Grafen, dessen Städtebau und „Urbanisierungspolitik " bald auch in den weiteren württembergischen Städten entgegentritt.

In Waiblingen, einem traditionsreichen Ort der salisch-staufischen Reichsgewalt, ist die württembergische Präsenz spätestens 1246/47 greifbar, als der Ort bereits städtisch geprägt erscheint ${ }^{23}$. Es muss zuvor ein deutlicher Ausbau des älteren Dorfes zur neuen Stadtanlage erfolgt sein, die eine Nikolaus-Kapelle erhielt, während die ältere Pfarrkirche St. Michael, Mutterkirche eines großen Sprengels, außerhalb der Stadtmauern verblieb. Im Mauerring allerdings beherrschte seit dem späteren 13. Jahrhundert wiederum die gräfliche Burg das Stadtgeschehen, wo des Öfteren auch die Grafen selbst mit ihren Amtsträgern residierten ${ }^{24} .1265$ erfahren wir erstmals von einem Schultheißen und einigen Vertretern typisch städtischer Berufe unter den Zeugen für die Grafen Ulrich und Eberhard von Württemberg, 1273 werden auch die universitas civium de Wabelingen und die civitas genannt ${ }^{25}$.

Auch in Schorndorf, das Graf Ulrich 1262 sein municipium nennt ${ }^{26}$, werden die Württemberger als Stadtherren greifbar; eine Burg als Herrschaftssitz wird angelegt, das ältere Schorndorf wird zur neuen Stadt ausgebaut und ebenfalls schon bald durch Mauern geschützt ${ }^{27}$. Die Pfarrkirche sollte auch hier zunächst außen vor im alten Dorf bleiben ${ }^{28}$. Die örtlichen staufischen Ministerialen werden in die württembergische Dienstmannschaft übernommen ${ }^{29}$, städtische Amtsträger, Richter und Schultheiß, die im Auftrag der Herrschaft fungieren, werden ebenfalls schon bald (ab 1264) genannt ${ }^{30}$. Da Ulrich um die Mitte des 13. Jahrhunderts auch über weitere benachbarte Burgen im Remstal verfügte, ebenso über die Vogtei des staufischen Hausklosters Lorch, erscheint das Remstal fest in seiner Hand ${ }^{31}$. Das municipium Schorndorf wird nun als Grenz- und Zollstation an der Ostgrenze des

23 Sönke Lorenz: Waiblingen - Ort der Könige und Kaiser (Gemeinde im Wandel 13). Waiblingen 2000. S. 123; - Ders., Die Herrschaft Württemberg (wie Anm. 4) S. 27. Vgl. daneben auch Ellen Widder: Die erste Stadt Württembergs? Waiblingen im Spätmittelalter. In: Waiblingen. Eine Stadtgeschichte. Hg. von Sönke Lorenz. Waiblingen [2005]. S. 81-147; hier: S. 97; danach Dies.: Waiblingen - eine Stadt im Spätmittelalter (Waiblingen in Vergangenheit und Gegenwart 16). Remshalden 2005 (hier mit entsprechenden Nachweisen).

${ }^{24}$ Das Land Baden-Württemberg, Bd.3 (wie Anm.22) S.562; Widder (wie Anm.23)

S. 112 .

25 Widder (wie Anm. 23) S. $101 \mathrm{f}$.

${ }^{26}$ WUB 6, Nr. 1639, S.39f. Internetpräsentation unter http://www.wubonline.de.

27 Der Mauerbau in Schorndorf war offenbar um 1300 weitgehend durchgeführt. Vgl. dazu Alois Schneider: Schorndorf (Archäologischer Stadtkataster Baden-Württemberg 36). Stuttgart 2011. S. $36 \mathrm{ff} ., 67 \mathrm{ff} . ;$ zur Burg S. $171 \mathrm{ff}$.

28 Erwin Franenknecht: Schorndorf im Mittelalter. In: Heimatblätter. Jahrbuch für Schorndorf und Umgebung 24 (2010) S. 26-123; hier: S. $62 \mathrm{ff}$.

${ }^{29}$ Siehe dazu auch den Beleg bei Lorenz, Waiblingen (wie Anm. 23) S. 123.

30 Franenknecht (wie Anm. 28) S. $47 \mathrm{ff}$.

31 Lorenz, Die Herrschaft Württemberg (wie Anm. 4) S. 27. 
württembergischen Territoriums ausgebaut; ihre Wehrhaftigkeit stand zunächst im Vordergrund der herrschaftlichen Ambitionen ${ }^{32}$.

In Cannstatt wurde die rechtliche Entwicklung zur Stadt im späteren 13. Jahrhundert wiederum vom Mauerbau begleitet. Von besonderer zentralörtlicher Bedeutung erscheint hier neben der herausragenden verkehrstopographischen Position, die sich auch als Zollstation verwerten ließ ${ }^{33}$, die alte Martinskirche von der „Altenburg“, die als Mutterkirche für eine große Anzahl von Filialen diente, bis sie 1321 in die Stuttgarter Stiftskirche eingepfarrt werden sollte ${ }^{34}$. Bekannt ist auch die traditionsreiche Bedeutung Cannstatts als Gerichtsort: Hier werden um 1300 erste sogenannte „Landtage“ der Württemberger abgehalten, wobei das Landgericht in der Burg „auf dem Stein“ tagte ${ }^{35}$. Diese wurde damals in die Neuanlage der Stadt einbezogen, während zahlreiche weitere Burgsitze und umliegende Dörfer aufgelassen wurden und wüst fielen. Ihre Gemarkungen wurden Cannstatt angegliedert, ihre Bewohner zogen dahin um ${ }^{36}$.

Das benachbarte Stuttgart, wo die Grafen von Württemberg bereits auch eine repräsentative Wasserburg von den badischen Markgrafen übernehmen konnten, mit einem benachbarten Kirchenbau, der bald zur Stiftskirche ausgebaut werden sollte, zeigt den herrschaftlichen Impuls am differenziertesten ${ }^{37}$. Hier wurde eine städtische Siedlung zur Residenz ausgebaut, deren Bedeutung als Herrschaftssitz um 1300 die Stammburg Wirtemberg überflügelte und mit einem Neubau der Stadtburg einherging. Mit der Verlegung des Stifts Beutelsbach bald darauf und der parallelen Transferierung der Familiengrablege wurde Stuttgart das herrschaftliche und sakrale Zentrum des sich formierenden Territoriums ${ }^{38}$ (Abb. 2).

Freilich kannten die gräflichen Itinerare bis ins 14. Jahrhundert noch keine festen Hauptstädte, sondern nur bevorzugte Aufenthaltsorte, und dies sind damals neben der Stammburg zunehmend die neuen Städte Waiblingen, Cannstatt, Schorndorf,

32 Vgl. zur Terminologie in Hinblick auf municipium jetzt die Ausführungen von Erwin Franenknecht zu Sindelfingen, das für das Jahr 1263 ebenfalls als municipium bezeichnet wird und damit auch ein städtebauliches Entwicklungsstadium greifen lässt: Erwin Franenknecht: Die Stadtgründungen der Pfalzgrafen von Tübingen im 13. Jahrhundert. In: 750 Jahre Sindelfingen. Hg. von Dorothee Ade. 2013 (im Druck). Vgl. ebd. auch die Ausführungen zur Sindelfinger „Gründungsurkunde“ von 1263 von Peter Rückert: Die Gründungsurkunde der Stadt Sinderfingen von 1263 (Edition und Kommentar, im Druck).

33 Werner Rösener: Grundherrschaften des Hochadels in Südwestdeutschland im Spätmittelalter. In: Die Grundherrschaft im späten Mittelalter. Bd. 2. Hg. von Hans Patze (Vorträge und Forschungen 27). Sigmaringen 1983. S. 87-176; hier: S. 121.

${ }^{34}$ Rückert, Wirtschaft und Verkehr (wie Anm.13) S. $67 \mathrm{f}$.

35 WUB 11, Nr.5467, S.394. Vgl. dazu auch Das Land Baden-Württemberg 3 (wie Anm.22) S. 39.

36 Das Land Baden-Württemberg 3 (wie Anm. 22) S. $40 \mathrm{f}$.

37 Schäfer (wie Anm. 18); hier vor allem S. $123 \mathrm{ff}$.

${ }^{38}$ Vgl. ausführlicher dazu Oliver Auge: Kongruenz und Konkurrenz: Württembergs Residenzen im Spätmittelalter. In: Der württembergische Hof im 15. Jahrhundert (wie Anm. 4) S. 53-74; hier: S. 59. 
Leonberg und immer dominanter eben Stuttgart ${ }^{39}$. Hier wird der gräfliche Hof mit den verschiedenen Hofämtern, Schreiber, Truchsess, Marschall, differenziert fassbar, ebenso erscheint ab 1263 ein consilium als ein festes Verwaltungsgremium, das an der Herrschaft beteiligt war und diese bald auch vertreten konnte ${ }^{40}$. Zudem nahm es die Funktion des Hofgerichts war. Seine Räte entstammten zunächst offensichtlich weitestgehend der württembergischen Ministerialität und lenkten die Hofverwaltung, aus der sich die Zentralverwaltung des wachsenden Territoriums zunehmend ausdifferenzieren sollte; wir kommen darauf zurück.

\section{Von der Stadt zum Amt: Territorialisierung und Landesverwaltung}

Halten wir als kurzes Zwischenfazit fest: Mit Ulrich I. wird eine regelrechte Städtepolitik der Grafen von Württemberg greifbar, die sich - orientiert an herkömmlichen Mustern dynastischer Städtegründungen - durch den systematischen Ausbau meist übernommener herrschaftlicher Positionen bzw. Zentralorte auszeichnete. Leonberg wird quasi als „suburbium“ neu angelegt, die übernommenen Orte werden als Städte ausgebaut, wobei sich die herrschaftliche Präsenz jeweils in der Einbeziehung einer Burg in den Mauerring widerspiegelt. Die Bevölkerung dieser neuen Städte kam zunächst aus der näheren Umgebung, wo einzelne Dörfer dafür verlassen wurden. Hier fixierten öfters nur die alten Dorfkirchen, die außerhalb der neuen Mauern verblieben, die hergebrachten kirchlichen Verbindungen. Sporadisch erscheinen in den Urkunden auch bald schon herrschaftliche Amtsträger vor Ort, welche die städtische Verwaltung übernahmen. Dabei tritt vor allem Stuttgart hervor, das als zentraler Sitz der Hofverwaltung zunehmend an Bedeutung gewann und zur wichtigsten Residenz der Grafen ausgebaut werden sollte.

Daneben wird die implizierte wirtschaftliche Bedeutung der neuen Städte von den Schriftzeugnissen hingegen kaum dokumentiert. Ihre rekonstruierbaren Grundrisse lassen freilich Marktplätze, wie bei Stuttgart (Abb.1), bzw. erweiterte Marktstraßen fassen, doch von entsprechenden Privilegierungen erwahren wir zunächst nichts. Herrschaftsverdichtung verbunden mit repräsentativer Wehrhaftigkeit, raumgreifende Verwaltung mit der Tendenz zur zentralörtlichen Steuerung stehen hier am Beginn des sich beschleunigenden württembergischen Territorialisierungsprozesses. Als dessen wesentlicher Gestalter gewinnt Graf Ulrich I. deutliches Profil: Noch vor seinem Tod 1265 wurde die Herrschaft Ulrichs durchaus schon flächenhaft verstanden: Per omnes terminos domini[i] nostri beschreibt ein Urkundentext von 1262 seinen Herrschaftsbereich ${ }^{41}$, freilich ohne diesen räumlich genauer zu fassen.

${ }^{39}$ Ebd. S. 60.

40 Ebd. S. 61.

${ }^{41}$ WUB 6, Nr. 1639, S. 39 f. Dazu ausführlicher Rückert, Dynastie (wie Anm. 4) S. 193. 


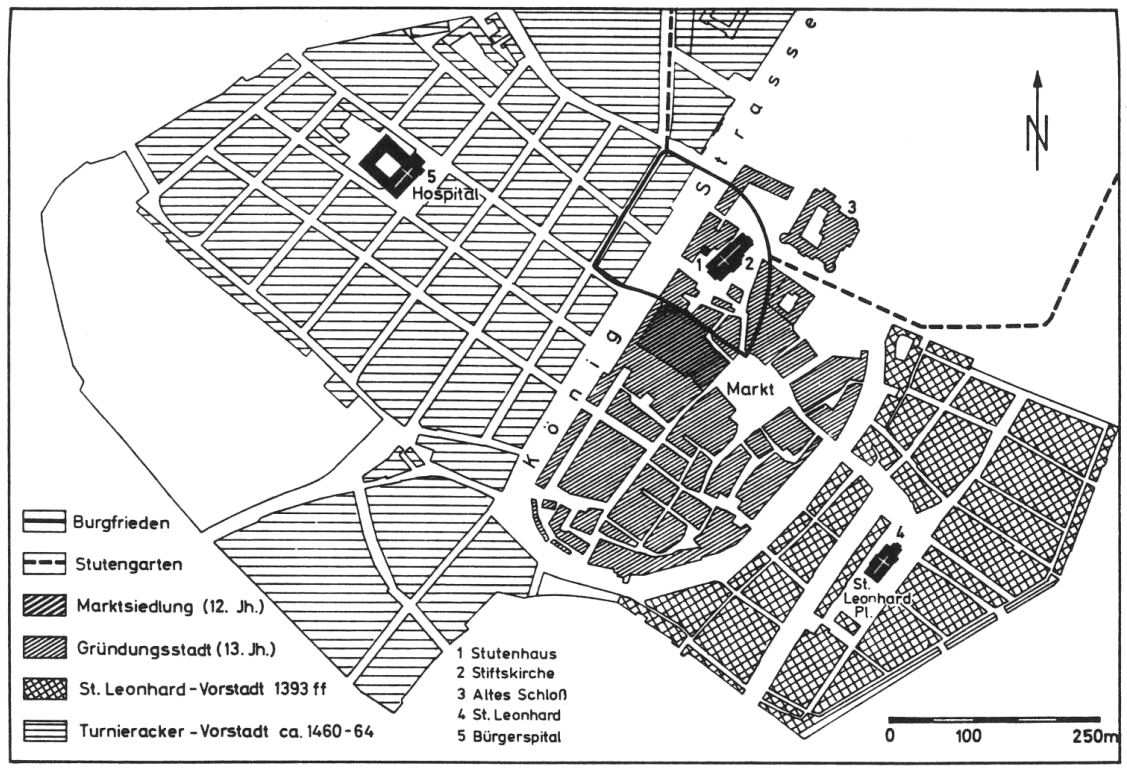

Abb. 1: Stuttgart im Spätmittelalter (nach Arnold Scheuerbrandt).

Wie konnte dieser erfolgreich beschrittene Weg im Kontext der zeitgemäßen Herrschaftsentwicklung weitergeführt werden - konstituiert durch die Vereinigung verschiedenartiger Herrschaftsrechte über Land und Leute und ausgerichtet an der Teilhabe am neu entwickelten Wirtschaftsleben, am Handelsverkehr, an städtischen Märkten und Geldwirtschaft? ${ }^{42}$ Die Handhabung und Umsetzung, moderner: die Inwertsetzung der unterschiedlichen Herrschaftsrechte durch eine möglichst effiziente Verwaltung war gefragt.

Doch während der Jahrzehnte um 1300 war die württembergische Politik durch vehemente Auseinandersetzungen mit dem Reich bzw. den Königen Rudolf von Habsburg und Heinrich VII. geprägt, die in Hinblick auf das angemaßte „staufische Erbe“ der Württemberger fast vorauszusehen waren. Bekanntlich wurde dabei mehrfach die Existenzfrage für Dynastie und Territorium gestellt und um die Legitimation ihrer Herrschaft vom Reich gestritten ${ }^{43}$. In diesem Kontext trat nicht nur die zentrale Bedeutung von Stuttgart hervor, die Übernahme zuvor badischer Besitzungen am mittleren Neckar konnte - vermittelt über erneuerte dynastische

42 Vgl. zur Problemstellung Dieter Mertens: Auf dem Weg zur politischen Partizipation? Die Anfänge der Landstände in Württemberg. In: Auf dem Weg zur politischen Partizipation? (wie Anm. 4) S. 91-102; hier: S. 94.

${ }^{43}$ Vgl. ausführlicher dazu Lorenz, Die Herrschaft (wie Anm. 4) S. $31 \mathrm{ff}$; daneben auch Rückert, Dynastie (wie Anm. 4) S. 196ff., sowie Widder (wie Anm.23) S. $118 \mathrm{ff}$. 
Verbindungen mit dem Markgrafenhaus - zwischenzeitlich sogar fortgesetzt werden. Deutlich wird hier die gemeinsame territorialpolitische Abstimmung in der räumlichen Orientierung: Während die Württemberger die Städte Backnang (1297) und Marbach (1302) ${ }^{44}$ sowie die Burg Reichenberg (1296) übernahmen ${ }^{45}$, orientierten sich die Markgrafen über den Schwarzwald nach Westen, zum Oberrhein $\operatorname{hin}^{46}$.

Als dann im Reichskrieg zwischen Graf Eberhard I. und Heinrich VII. die Burg Wirtemberg und die Stadt Marbach zerstört waren, kapitulierten 1312 die württembergischen Städte Stuttgart, Leonberg, Waiblingen, Schorndorf, Backnang, Neuffen, Asperg und Markgröningen ${ }^{47}$ - von Cannstatt und Urach hören wir nichts, doch erfassen wir damit sicher weitgehend das von den Städten repräsentierte, inzwischen stark angewachsene württembergische Territorium. Die damals von den einzelnen Städten mit der Reichsstadt Esslingen als Führerin des Reichsaufgebots geschlossenen Vergleiche zeigen deren Repräsentanten: Schultheiß, Richter, Rat und Bürger treten hierbei gemeinsam auf, wobei der Rat in Leonberg, Waiblingen und Schorndorf nun erstmals in Erscheinung tritt ${ }^{48}$. In wieweit die Städte in dieser Situation einen aktiven Herrschaftswechsel betrieben, um sich aus der württembergischen Herrschaft zu lösen und unter Esslinger Schutz zu stellen, wie jüngst betont ${ }^{49}$, erscheint sicher fragwürdig. Jedenfalls konnte nur durch den überraschenden Tod des Königs mit den Städten auch die württembergische Herrschaft gehalten werden ${ }^{50}$. Eberhard gelang es daran anschließend sogar, noch weitere bedeutende territoriale Gewinne zu machen, besonders prestigeträchtig Burg Hohenstaufen mit der Stadt Göppingen ${ }^{51}$.

Bieten die Dokumente zu den Reichskriegen und Erwerbungen Graf Eberhards auch kaum Angaben zu den Strukturen seiner Herrschaft bzw. seines Besitzes, so können wir doch zumindest beispielhaft erkennen, wie diese Herrschaft über die Neuerwerbungen in der Fläche organisiert wurde: Die Dienstmannen auf den Burgen und in den Städten wurden größtenteils übernommen, so wie auf Burg Reichenberg von den Badenern ${ }^{52}$, die dazu gehörigen Orte oder Gebiete wurden offensichtlich als Organisationseinheiten betrachtet und es wurde versucht, sie quasi als einzelne Bausteine dem württembergischen Territorium anzugliedern. Inwie-

44 Die entsprechenden Urkunden finden sich unter dem Bestand der Württembergischen Regesten (= WR), vgl. HStA Stuttgart A 602 Nr. 10642 f.

${ }_{45} \mathrm{Vgl}$. dazu ausführlicher den Beitrag von Sönke Lorenz in diesem Band.

46 Ausführlicher dazu der Beitrag von Heinz Krieg in diesem Band.

47 Vgl. Lorenz, Die Herrschaft (wie Anm.4) S.33; - Franenknecht, Schorndorf (wie Anm. 28) S. $58 \mathrm{ff}$.

${ }^{48} \mathrm{Vgl}$. die Angaben für Schorndorf bei Schneider (wie Anm. 27) S. 39, für Waiblingen bei Widder (wie Anm. 23) S. 121.

49 Widder (wie Anm. 23) S. 126; - Franenknecht, Schorndorf (wie Anm. 28) S. 59.

50 Rückert, Dynastie (wie Anm. 4) S. 32.

51 Lorenz, Die Herrschaft (wie Anm. 4) S 34.

52 Rückert, Dynastie (wie Anm. 4) S. 198. 
weit damit organisatorische, personelle oder bauliche Veränderungen in den Städten einhergingen, entzieht sich zunächst weitgehend unserer Kenntnis. Doch halten wir fest, dass die prominente Stellung der Städte in ihrer zentralen Funktion als neue Mittelpunkte von Verwaltung- und Gerichtsbezirken bald flächendeckend hervortritt.

Ein aussagekräftiges Beispiel dafür mag genügen: Als Graf Eberhard I. seine territorialpolitische Expansion in den Schwarzwald um 1320 mit der Erwerbung der Neuenbürg aus Reichsbesitz abrunden konnte, ließ er anschließend zu ihren Füßen eine neue Stadt, ein municipium an der Enz anlegen, das wiederum den Namen der Burg übernahm: Neuenbürg ${ }^{53}$. Auch diese neue Stadt wurde gleich mit Mauern befestigt, die Marktstraße bildet noch immer die Hauptachse der Siedlung, die sich mit ihrem langgestreckten, leiterartigen Grundriss ins steile Enztal einschmiegt (Abb.6) - deutliche Parallelen zur angesprochenen Stadtgründung von Leonberg werden augenscheinlich.

Neuenbürg, das bereits aufgrund seiner verkehrstopographischen Situation als neue Grenz- und Zollstation des württembergischen Territoriums besondere Bedeutung besaß, wurde nun systematisch als Verwaltungsmittelpunkt der umliegenden württembergischen Besitzungen ausgebaut. Auch von hier aus wurde die Formierung eines Amtes betrieben; ab 1345 erscheint ein württembergischer Vogt auf der Burg, der offenbar auch die gerade übernommenen Vogteirechte über das benachbarte Zisterzienserkloster Herrenalb wahrnehmen sollte ${ }^{54}$.

In Schorndorf, das wir ja bereits ebenfalls als municipium, als Grenz- und Zollstation des württembergischen Territoriums, kennengelernt haben, ist der Urbanisierungsprozess damals bereits weiter fortgeschritten. Hier tritt, wie erwähnt, schon ab dem Ende des 13. Jahrhunderts eine „verfasste Bürgergemeinde“ mit Schultheiß, Richtern und Rat aus den Reihen der Stadtbürger entgegen, die zunächst im Auftrag des Grafen seine Stadt verwalteten ${ }^{55}$. Die von der jüngeren Forschung nachdrücklich betonte zunehmende Verselbständigung und „Autonomie“ der städtischen Verwaltung blitzt zwar gerade in Krisensituationen beispielhaft auf $^{56}$, ihr Handlungsspielraum wird aber nach wie vor durch den maßgeblichen herrschaftlichen Rahmen bestimmt.

Die herrschaftliche Präsenz wird zumal in den örtlichen Funktionären konkret fassbar: Die Schultheißen, dann die Vögte und Keller, wie auch die Pfarrer aus dem engsten höfischen Umfeld der Grafen ${ }^{57}$, zeigen zunächst ein herrschaftliches Netz-

53 Rückert, Dynastie (wie Anm. 4) S. 200.

${ }^{54}$ Peter Rückert: Neuenbürg: Burg, Stadt und Amt im Mittelalter. In: Der Nordschwarzwald. Von der Wildnis zur Wachstumsregion. Hg. von Sönke Lorenz. Filderstadt 2001. S. 74-82; hier: S. 78.

${ }^{55}$ Franenknecht, Schorndorf (wie Anm. 28) S. 47 ff.; - Schneider (wie Anm. 27 ) S. 41.

${ }^{56}$ So gerade in Hinblick auf Waiblingen betont von Widder (wie Anm. 23) S. $123 \mathrm{ff}$.; - vgl. dazu auch Schneider (wie Anm. 28) S. $39 \mathrm{f}$.

${ }^{57}$ Franenknecht, Schorndorf (wie Anm. 28) S. 82 f.; - Schneider (wie Anm. 27) S. 47. 


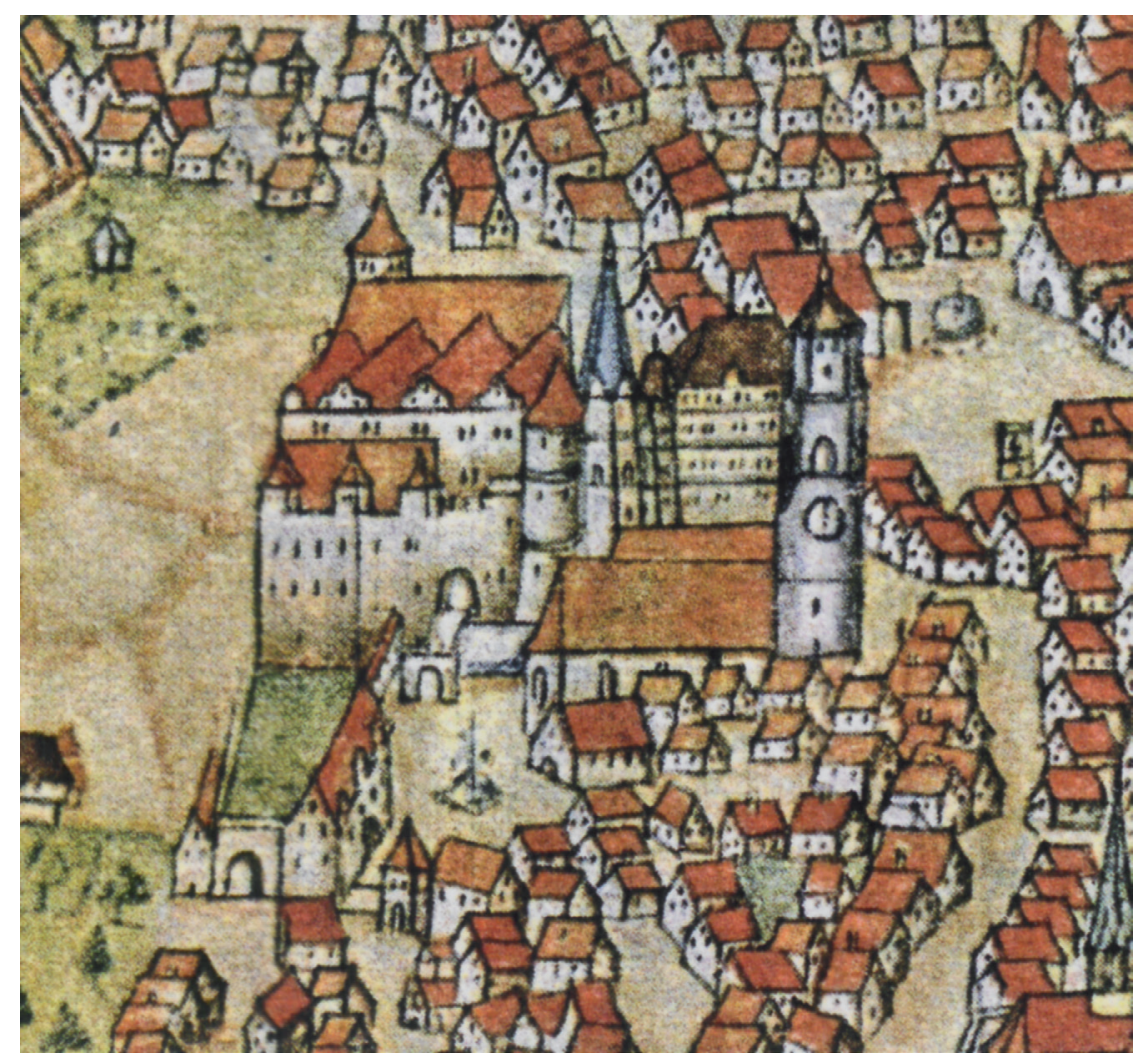

Abb. 2: Das herrschaftliche Zentrum von Stuttgart mit Altem Schloss und Stiftskirche. Ausschnitt aus dem Forstkartenwerk von Andreas Kieser, 1680 (Reproduktion; Vorlage: Landesmedienzentrum Baden-Württemberg). 


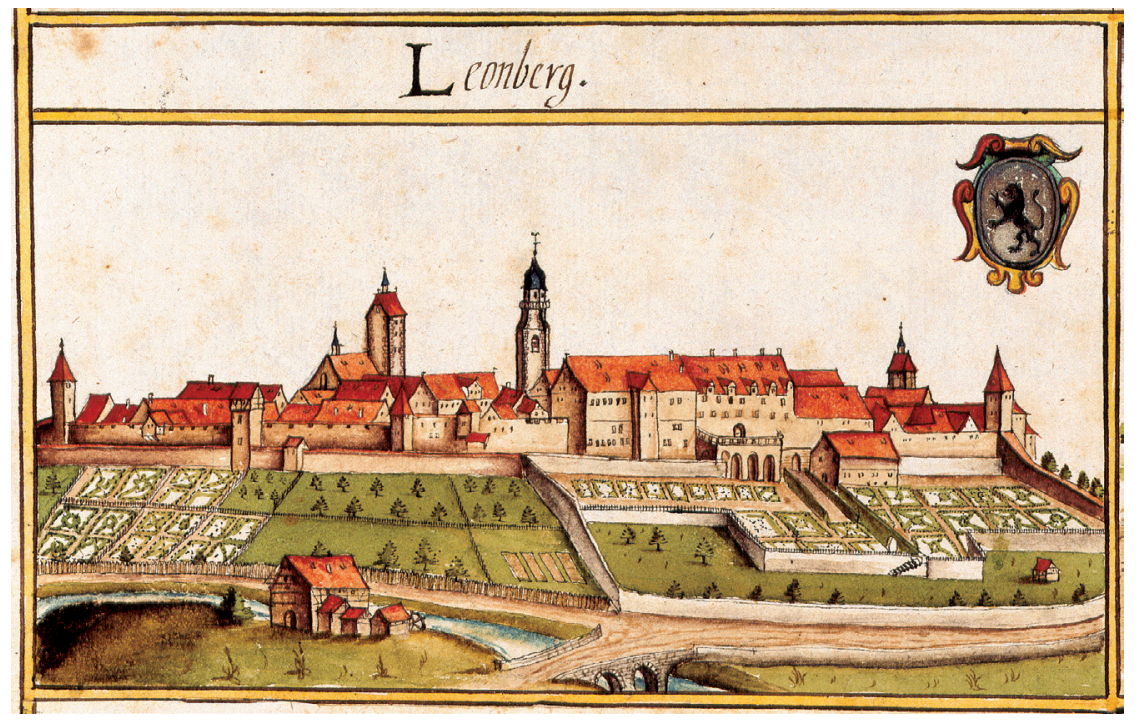

Abb. 3: Ansicht von Leonberg aus dem Forstlagerbuch von Andreas Kieser, 1682 (HStA Stuttgart H 107/8, Bd. 5, Bl.3).

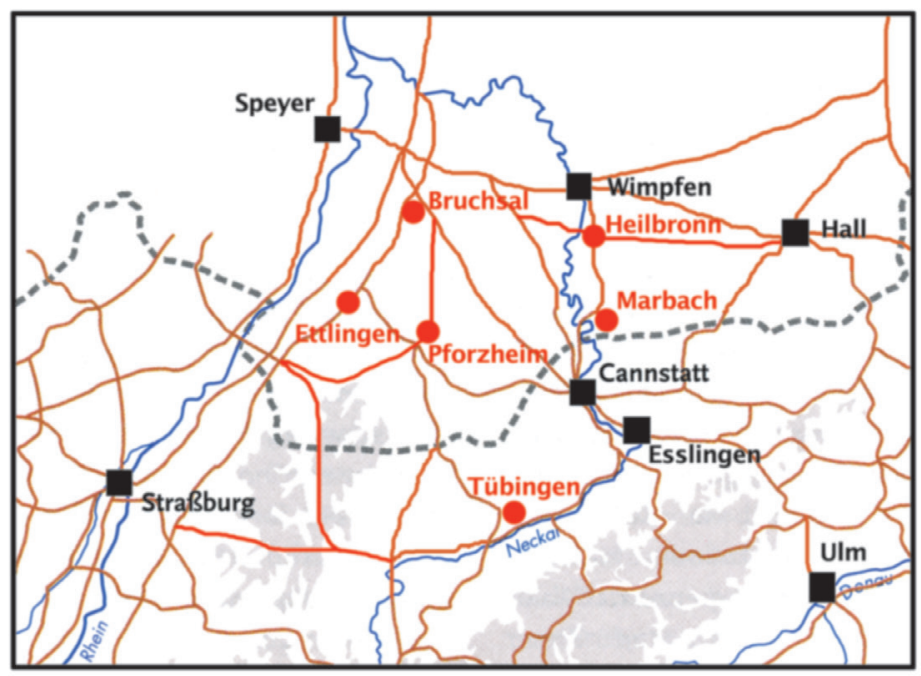

frühmittelalterliche Zentralorte

hochmittelalterliche Zentralorte

Abb. 4: Die Verkehrslandschaft am mittleren Neckar im Hochmittelalter (Entwurf: Peter Rückert, grafische Umsetzung: Martina Böhm). 


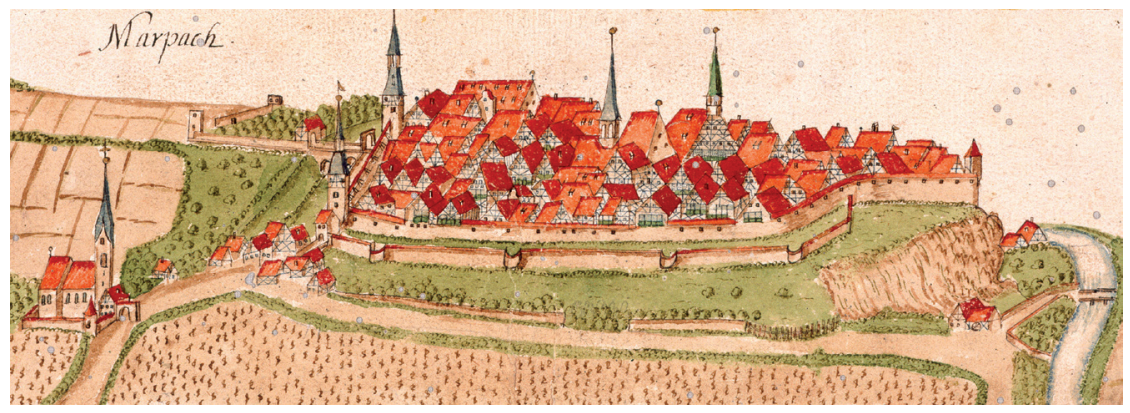

Abb. 5: Ansicht von Marbach aus dem Forstlagerbuch von Andreas Kieser, 1686 (HStA Stuttgart H 107/14, Bd. 6, Bl. 5).

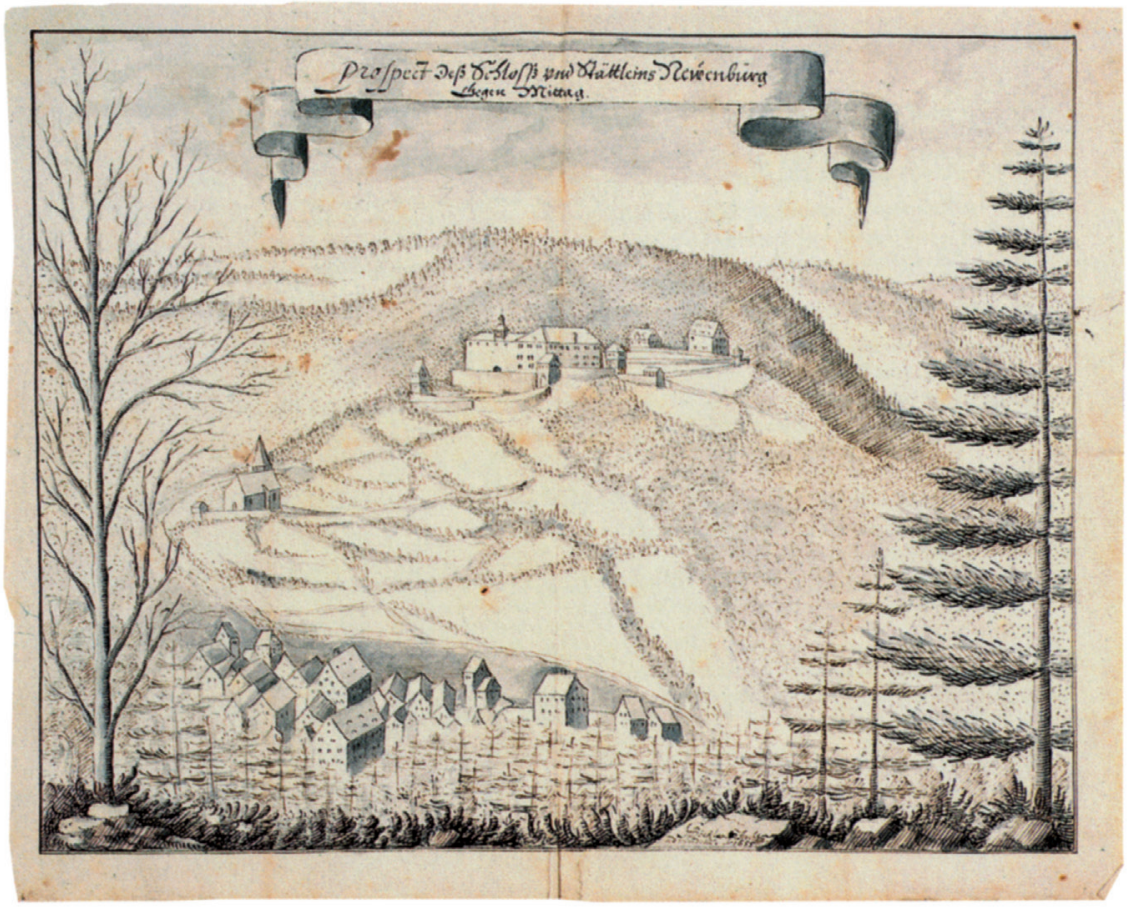

Abb. 6: Ansicht von Schloss und Stadt Neuenbürg, 1655 (Vorlage: HStA Stuttgart). 


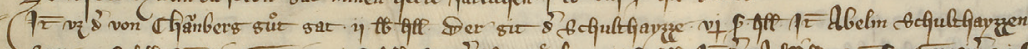

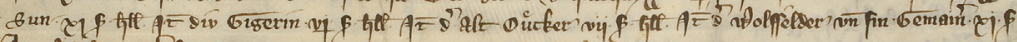

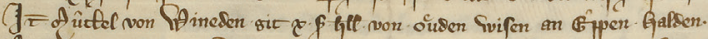

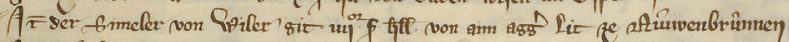

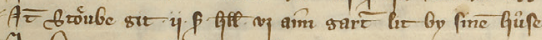

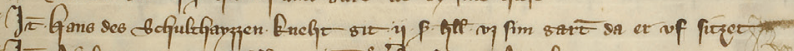

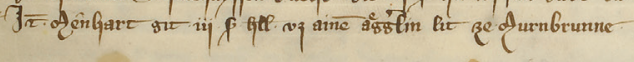

马ु

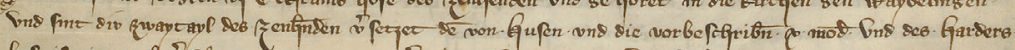

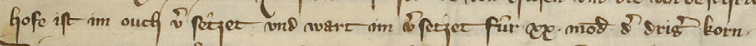

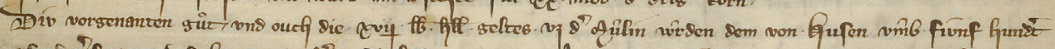

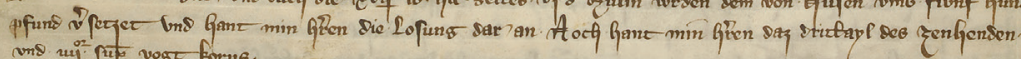

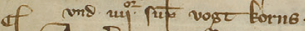

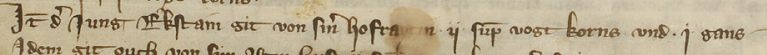

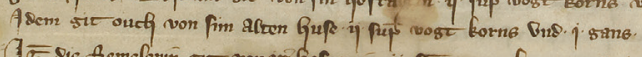

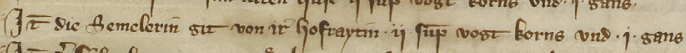

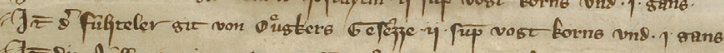

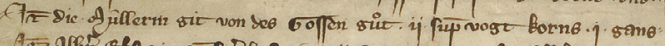

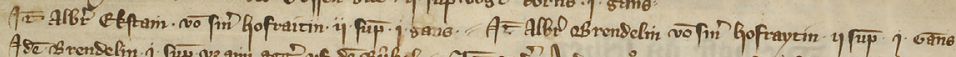

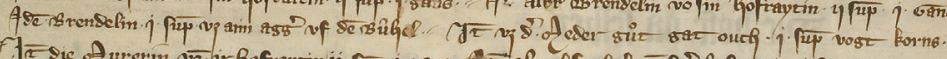

Fुन

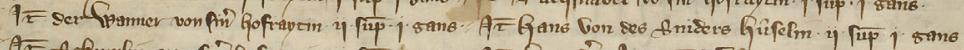

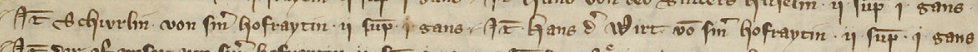

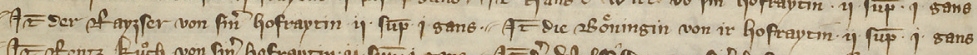

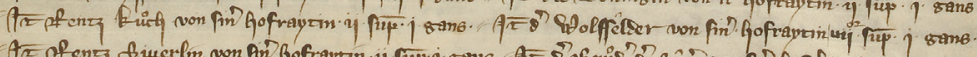

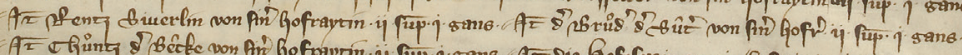

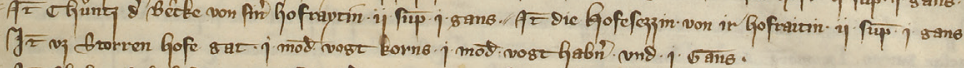

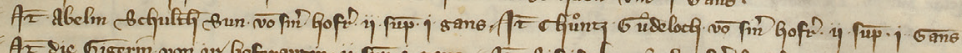

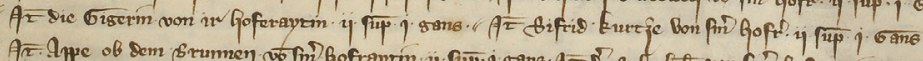

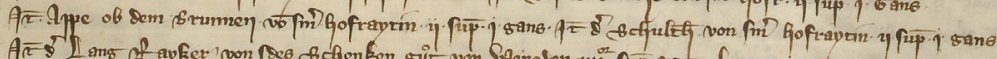

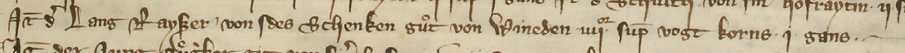

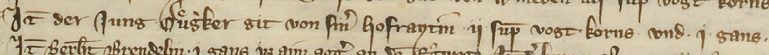

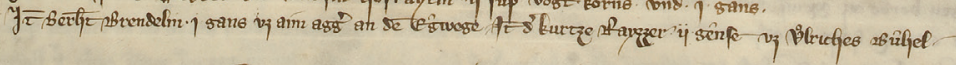

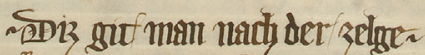

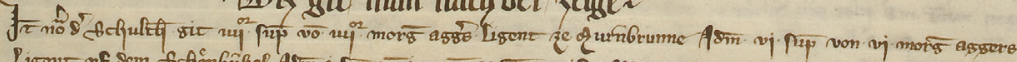

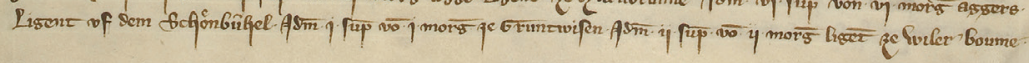


werk, eine Klientel, welche die maßgeblichen politischen Funktionen in den Städten besetzt. Diese herrschaftlichen Funktionäre beanspruchen ihre politische und rechtliche Kompetenz auch für die Dörfer der Umgebung, so dass ab der Mitte des 14. Jahrhunderts einzelne Verwaltungsbezirke greifbar werden. Jetzt erscheinen neben und bald anstelle der städtischen Schultheißen Vögte als zentrale herrschaftliche Amtsträger - damit verbinden wir die Entwicklung von der Stadt zum Amt: der Vogt sollte zugleich als Stadtvorsteher wie Bezirksverwalter seiner Herrschaft dienen ${ }^{58}$. Die Stadt wurde zum Zentrum eines Gerichts-, Verwaltungs- und Wehrbezirks unter seiner Führung ${ }^{59}$.

Gleichzeitig fassen wir nun um 1350 erstmals eine ausgeprägte Schriftkultur, die zunächst die Verwaltungskompetenz der herrschaftlichen Zentralverwaltung in Württemberg widerspiegelt: Angegliedert an die Stuttgarter Residenz tritt uns eine mit zahlreichen Schreibern besetzte gräfliche Kanzlei entgegen, die nicht nur das Urkundenwesen prägte ${ }^{60}$, sondern jetzt auch mit umfassend konzipierten Serien von Urbaren und Lehensbüchern hervortritt. Hier sollten Herrschaftsrechte, Besitzstand und Einkünfte ebenso flächendeckend dokumentiert werden wie die personalrechtlichen Herrschaftsbindungen. Daneben greifen wir auch den „Hofmeister" quasi als Verwaltungschef des Landes, dessen Bindung zum gräflichen Hof ebenso wie seine Funktion als oberster Amtsträger der Landesverwaltung deutlich wird ${ }^{61}$.

In den leider nur zum Teil erhaltenen Urbaren aus den Jahren um 1350 werden die räumlichen Verwaltungsstrukturen der Herrschaft Württemberg erstmals deutlich (Abb.7): Diese Urbare wurden jeweils für einen Bezirk angelegt, hier lateinisch als advocatia, deutsch als „Pflege“ bezeichnet. Die Bezeichnung „Amt“

58 Vgl. Grube (wie Anm.7); dazu auch Christian Kübler: Ehrbarkeit, Landschaft und Amt im spätmittelalterlichen Württemberg. In: Landschaft, Land und Leute. Politische Partizipation in Württemberg 1457 bis 2007. Begleitbuch und Katalog zur Ausstellung des Landesarchivs Baden-Württemberg, Hauptstaatsarchiv Stuttgart, und des Landtags von Baden-Württemberg. Bearb. von Peter Rückert. Stuttgart 2007. S. 47-50. - Vgl. daneben jetzt Nina Kühnle: Richter, Vögte, Landschaftsvertreter. Die „Ehrbarkeit“ im spätmittelalterlichen Württemberg. In: Mittler zwischen Herrschaft und Gemeinde. Die Rolle von Funktions- und Führungsgruppen in der mittelalterlichen Urbanisierung Zentraleuropas. Hg. von Elisabeth Gruber u. a. Innsbruck u. a. 2012. S. 217-243.

${ }^{59}$ Zum Amtsbereich der Vögte vgl. ausführlicher zuletzt Volker Trugenberger: Der Erwerb der Herrschaft Schalksburg 1403 und die württembergische Territorialpolitik. In: Die Herrschaft Schalksburg zwischen Zollern und Württemberg. Hg. von Andreas Zekorn/Peter Thaddäus Lang/Hans Schimpf-Reinhardt. Epfendorf 2005. S. 105-138.; hier: S. 116.

60 Dazu Peter-Johannes Schuler (Bearb.): Regesten zur Herrschaft der Grafen von Württemberg 1325-1378 (Quellen und Forschungen aus dem Gebiet der Geschichte NF Heft 8). Paderborn u.a. 1998. Vgl. auch die hier nachgewiesenen Lehensverzeichnisse Nr. 224-264, 609-663, 681-691 und spätere. Ausführlicher zu diesem Kontext: Matthias Miller: Mit Brief und Revers: Das Lehenswesen Württembergs im Spätmittelalter. Quellen, Funktion, Topographie (Schriften zur Südwestdeutschen Landeskunde 52). Leinfelden-Echterdingen 2004.

${ }^{61}$ Lorenz, Die Herrschaft (wie Anm. 4), S. 60. 
sollte dann erst im 15. Jahrhundert folgen ${ }^{62}$. Ihre Beschreibungen sind nach Orten gegliedert; Hauptorte sind die Städte, hier: Stuttgart, Leonberg, Waiblingen, Asperg. Dazu wurden jeweils alle Güter, Rechte und Einkünfte der Grafen von Württemberg aufgeführt ${ }^{63}$. Damit wird erstmals auch die Abgrenzung dieser Bezirke untereinander wie auch ihr Zustand fassbar (Abb. 8): Gerade für die Pflege Asperg, die sich über den Neckar hinweg bis nach Kirchberg an der Murr erstreckte - allerdings ohne Marbach und Umgebung - wird eine Momentaufnahme greifbar. Zwischen die Grenzen der einzelnen Pflegen schob sich oft noch fremder Besitz, hier vor allem des Klosters Bebenhausen. Gleichzeitig erscheint etwa für die Pflege Waiblingen der auch späterhin greifbare Umfang des Amtes schon weitgehend fixiert ${ }^{64}$.

Leider hat sich aus der angesprochenen Urbarserie keines für das Amt Marbach erhalten, das den ausschnitthaften Eindruck von der räumlichen Struktur der württembergischen Territorialverwaltung sinnfällig hätte ergänzen können. Doch bieten sich bereits bald, im Kontext der Heirat Graf Eberhards III. mit Antonia Visconti im Jahr 1380, einschlägige Informationen dazu. Bleiben wir also noch kurz in Marbach und verfolgen diese spektakulären Vorgänge um seine informative Amtsgeschichte: Lagen die Anfänge der Stadtgründung über dem Neckar auch schon weit über ein Jahrhundert zurück ${ }^{65}$, und hatte die Stadtburg auch bereits des Öfteren den württembergischen Herren zum Aufenthalt gedient ${ }^{66}$, sollte sich die besondere Bedeutung Marbachs doch erst im späteren 14. Jahrhundert zeigen. Jetzt lernen wir neben dem Marbacher Schultheißen den Vogt Konrad Klein kennen, der aus Kornwestheim stammte und dort bereits als Vogt amtierte, bevor er von 1351 bis 1370 die Ämter Asperg und Marbach versah ${ }^{67}$ - eine Personalunion, die daran anschließend allerdings wieder die Loslösung des Amtes Marbach zur Folge hatte.

Als Graf Eberhard III. im Jahr 1380 mit der Mailänder Prinzessin verheiratet wurde, wurden Antonia jährliche Einkünfte aus dem Nordteil der Grafschaft zur Nutznießung übertragen, als Widerlegung für ihre reiche Mitgift ${ }^{68}$. Die Beschrei-

${ }^{62}$ Vgl. die Edition von Karl Otto Müller (Bearb.): Altwürttembergische Urbare aus der Zeit Graf Eberhards des Greiners (1344-1392) (WGQ 22). Stuttgart/Berlin 1934; hier S. 35\%.

${ }^{63}$ Ebd. S. 36*. Vgl. daneben für Waiblingen Widder (wie Anm. 23) S. $126 \mathrm{ff}$.

64 Widder (wie Anm.23), S.128. An dieser Stelle könnten weitere regionale Untersuchungen ansetzen, um zu noch konkreteren Erkenntnissen zu führen.

${ }^{65}$ Vgl. den Beitrag von Sönke Lorenz in diesem Band.

66 Vgl. Paul Sauer: Marbach im Mittelalter und zu Beginn der frühen Neuzeit. In: Geschichte der Stadt Marbach am Neckar. Bd.1 (bis 1871). Hg. von Albrecht Gühring u.a. Ubstadt-Weiher 2002. S. 145-230; hier: S. $151 \mathrm{ff}$. Zu den beeindruckenden archäologischen Befunden der beim Stadtbrand 1693 zerstörten Marbacher Burg vgl. jetzt Hartmut Schäfer: Archäologische Untersuchungen in Marbach. In: Wirtschaft, Handel und Verkehr im Mittelalter (wie Anm. 13) S. 171-188; hier: S. 177ff.

${ }^{67}$ Hesse (wie Anm. 5) S. 699.

${ }^{68}$ Zum Folgenden siehe ausführlicher Ulrich Schludi: Mailänder Stolz und schwäbische Sparsamkeit - Die Heiratsverhandlungen für Antonia Visconti und Eberhard III. von Württemberg in den Jahren 1379/80. In: Die Visconti und der deutsche Südwesten. Kultur- 


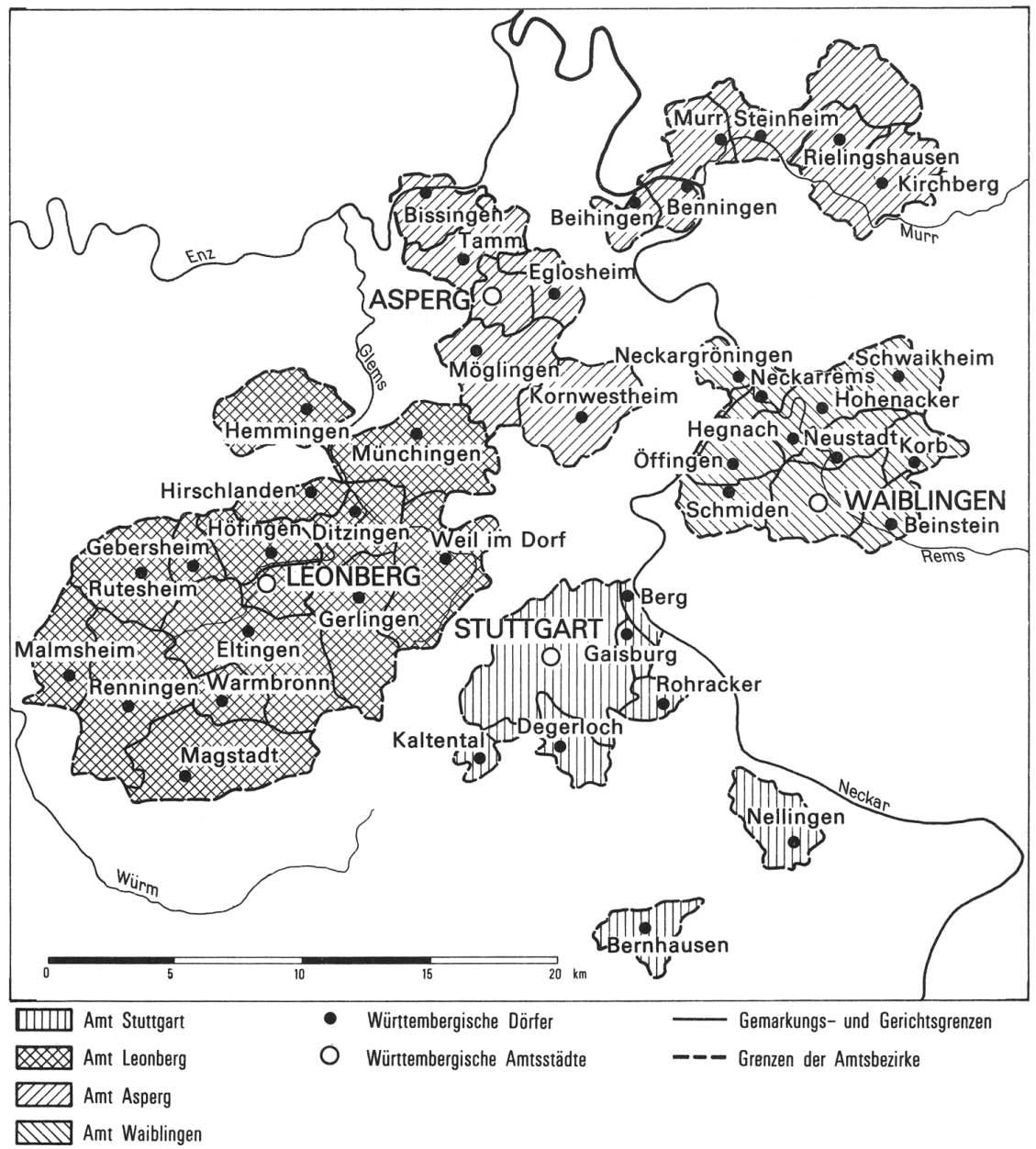

Abb. 8: Ämter in der Grafschaft Württemberg um 1350 (nach Werner Rösener).

bung dieser Güter führt nicht nur die aktuelle wirtschaftliche Situation der Grafschaft eindrücklich vor Augen, sondern vor allem auch den unterschiedlichen Grad ihrer herrschaftlichen Durchdringung und Verwaltungsorganisation: Dem Amt Marbach - officium seu advocatia in Marpbach - mit Einkünften aus 15 Orten, von Möglingen über Bissingen bis Kirchberg und Wolfsölden, stehen die civitates Güg-

transfer im Spätmittelalter. Hg. von Peter Rückert/Sönke Lorenz (Tübinger Bausteine zur Landesgeschichte 11). Ostfildern 2008. S. 131-152. 
lingen und Brackenheim mit jeweils fünf zugeordneten Orten gegenüber (Abb. 9). Von der civitas Kleingartach und dem castrum Magenheim werden damals jeweils nur zwei Orte verwaltet. Das spätere Amt Bietigheim tritt gar nur als terra auf, dessen Einkünfte noch von einem städtischen Schultheißen eingetrieben werden mussten, und wo noch andere Grundherren begütert waren, wie Ulrich Schludi gezeigt hat ${ }^{69}$. Daneben standen weitere Orte, wo Württemberg lediglich Teilrechte besaß und entsprechend geringe Einkünfte bezog.

Abgesehen von Lauffen, Großbottwar und Backnang umfassten die genannten Güter immerhin den ganzen Norden der damaligen Grafschaft und lassen in ihren etwa 7.000 Gulden an jährlichen Einkünften die recht geringe Wirtschaftskraft dieses Teils von Württemberg erkennen, die nun der Gräfin Antonia zur Verfügung stehen sollte ${ }^{70}$. Marbach und sein Amtsbezirk, der sich jetzt weit über den Neckar bis ins einstige Amt Asperg erstreckte, bildete hier das deutliche Zentrum der württembergischen Verwaltung und sollte sich als solches auch in der Folgezeit etablieren.

Unterstützt wurde diese zentrale Bedeutung von der Wirtschaftskraft der Stadt und der Attraktivität ihres Marktes, der ja bereits lange Tradition besa $\beta^{71}$. Dass es damals in Marbach tatsächlich große Vermögen zu verwalten galt, zeigt der berühmte Marbacher Münzschatz, der kurz vor 1400 in der Altstadt verborgen wurde und auffälligerweise zahlreiche Mailänder Goldmünzen enthielt ${ }^{72}$. Sie verweisen auf den großartigen Brautschatz der Antonia Visconti und den internationalen Geldumlauf seiner Zeit; seinen einstigen Besitzer verraten sie leider nicht.

Bemerkenswerterweise aber baut die württembergische Herrschaft damals in Marbach kräftig aus: Die Mauern der alten Burg werden um 1400 sorgfältig abgetragen, an ihrer Stelle wird ein großzügiges, repräsentatives „Stadtschloss“ aufgebaut, woran sich offenbar bald auch ein ummauerter Tiergarten anschließen sollte ${ }^{73}$ (Abb. 5): Die herrschaftliche Bedeutung des Ortes erhielt bauliche Gestalt, auch wenn die Präsenz der Grafen zunächst kaum fassbar ist ${ }^{74}$.

Die Bedeutung der Amtmänner oder Vögte wurde jetzt jedenfalls in der Vertretung der Herrschaft wie in der Verantwortung für ihr Land gesehen: Die Amtmänner, die die herrschaft von Wirtemberg und daz land, beide diener und arme lute, verantwurten und verteidigen nach ir notdurft, heißt es im Kontext der Auseinan-

69 Ebd. Vgl. dazu auch Antonia Visconti (†1405). Ein Schatz im Hause Württemberg. Begleitbuch und Katalog zur Ausstellung des Landesarchivs Baden-Württemberg, Hauptstaatsarchiv Stuttgart. Bearb. von Peter Rückert. Stuttgart 2005. S. 195 f.

70 Schludi (wie Anm. 68) S. $141 \mathrm{ff}$.

${ }^{71}$ Rückert, Wirtschaft (wie Anm. 13) S. $68 \mathrm{ff}$.

72 Zuletzt dazu Ulrich Klein: Marbach im Spiegel der südwestdeutschen Münz- und Geldgeschichte. In: Wirtschaft, Handel und Verkehr im Mittelalter (wie Anm.13) S.115145; hier: S. $120 \mathrm{f}$.

73 Schäfer (wie Anm. 66) S. $182 \mathrm{f}$.

74 Vgl. ausführlicher dazu Antonia Visconti (wie Anm. 69) S. $196 \mathrm{ff}$. 


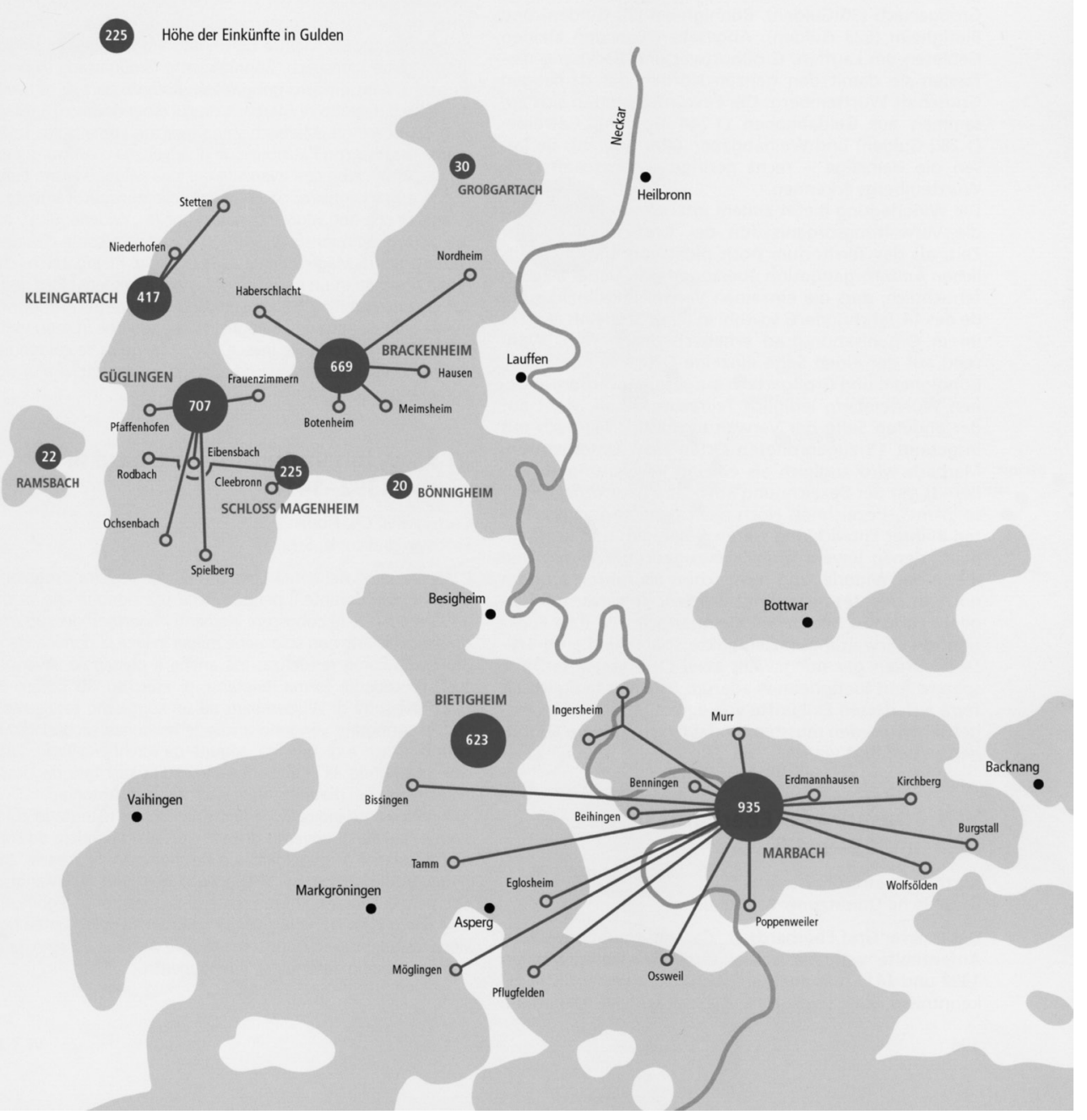

Abb. 9: Die Einkünfte der Antonia Visconti aus den Gütern ihrer Widerlegung (Entwurf: Ulrich Schludi, grafische Umsetzung: Katharina Schmid). 
dersetzungen zwischen den Grafenbrüdern Eberhard II. und Ulrich IV. 1361 ${ }^{75}$, wobei hier erstmals auch von der „Grafschaft Württemberg“ die Rede ist ${ }^{76}$. In dieser Krisensituation der Herrschaft treten auch ihre Räte hervor, deren großer Einfluss auf die Herrschaftsbildung und -kontinuität des Hauses Württemberg deutlich wird. Graf Eberhard ließ damals die Räte seines Bruders als Urheber der Streitigkeiten gefangen setzen, weil diese ihn und seinen Sohn aus der Herrschaft treiben wollten. Anschließend nahm er mit Gewalt alle Burgen und Städte ein, die ihnen gemeinsam zustanden und ließ sich schwören ${ }^{77}$. Nach dem Ausgleich des Bruderzwists sollten die Vertreter der Städte versichern, dass sie - sollte einer der Brüder Teile der Grafschaft entfremden wollen - dem anderen beistehen sollten ${ }^{78}$. Die politische Bedeutung der Städte und ihrer Vertreter für die Einheit des Landes Württemberg ist offenkundig.

Halten wir fest: Die Räte und Amtmänner - oft in ein und derselben Person machen jetzt Politik in der Grafschaft Württemberg. Sie stellen die herrschaftliche Klientel, die zunehmend stärker nicht mehr nur auf die Herrschaft, sondern auch auf die Landesinteressen, „Land und Leute“, verpflichtet wird. Mehr und mehr werden diese adeligen Amtmänner und Vögte allerdings bald durch das amtsstädtische Bürgertum verdrängt werden, so dass ihnen im späteren 15. Jahrhundert hier fast nur mehr militärische Aufgaben als Obervögte bleiben sollten. Als Diener und Räte am Hof freilich waren sie weiterhin gefragt ${ }^{79}$, wie das berühmte Bild der in mehreren Fassungen immer wieder aktualisierten „Ratssitzung“ Graf Eberhards III. eindrücklich zeigt ${ }^{80}$.

Die Verbindung der hohen Amtsinhaber zum gräflichen Hof - ob in der Zentralverwaltung, etwa als Hofmeister, oder Lokalverwaltung, als Amtmann bzw. Vogt - sollte also erhalten bleiben. Der Zusammenhang zwischen Lehensbindung und Ratsfunktion wird in Württemberg ebenso anhaltend deutlich, wie etwa in der Kurpfalz, gerade in problematischen Zeiten, wenn die Herrschaft vertreten werden musste: Als der Vormundschaftsrat für die beiden unmündigen Söhne der Gräfin Henriette die württembergischen Regierungsgeschäfte in den 1420 er Jahren führte, setzte sich dieser vor allem aus dem Niederadel der bekannten Familien zusammen. Damals wurde auch das Rechnungswesen neu geordnet, wobei diese „Statthalter und Räte“ von den anderen nichtadeligen „Dienern“ der Herrschaft unterschieden

75 Zitat nach Lorenz, Vom herrschaftlichen Rat (wie Anm. 4) S. 7.

76 Lorenz, Die Residenz (wie Anm. 4) S. 39.

77 Vgl. Barbara Hammes: Ritterlicher Fürst und Ritterschaft. Konkurrierende Vergegenwärtigung ritterlich-höfischer Tradition im Umkreis südwestdeutscher Fürstenhöfe 13501450 (VKgL B 185). Stuttgart 2011. S. 160.

78 Trugenberger, „Ob den portten ...“" (wie Anm. 5) S.132.

79 Hammes (wie Anm. 77) S. 159.

80 Ausführlich dazu Peter Rückert: Die „Ratssitzung“ Graf Eberhards III. von Württemberg - Politische Partizipation im Bild? In: Auf dem Weg zur politischen Partizipation? (wie Anm. 4) S. 137-154. 


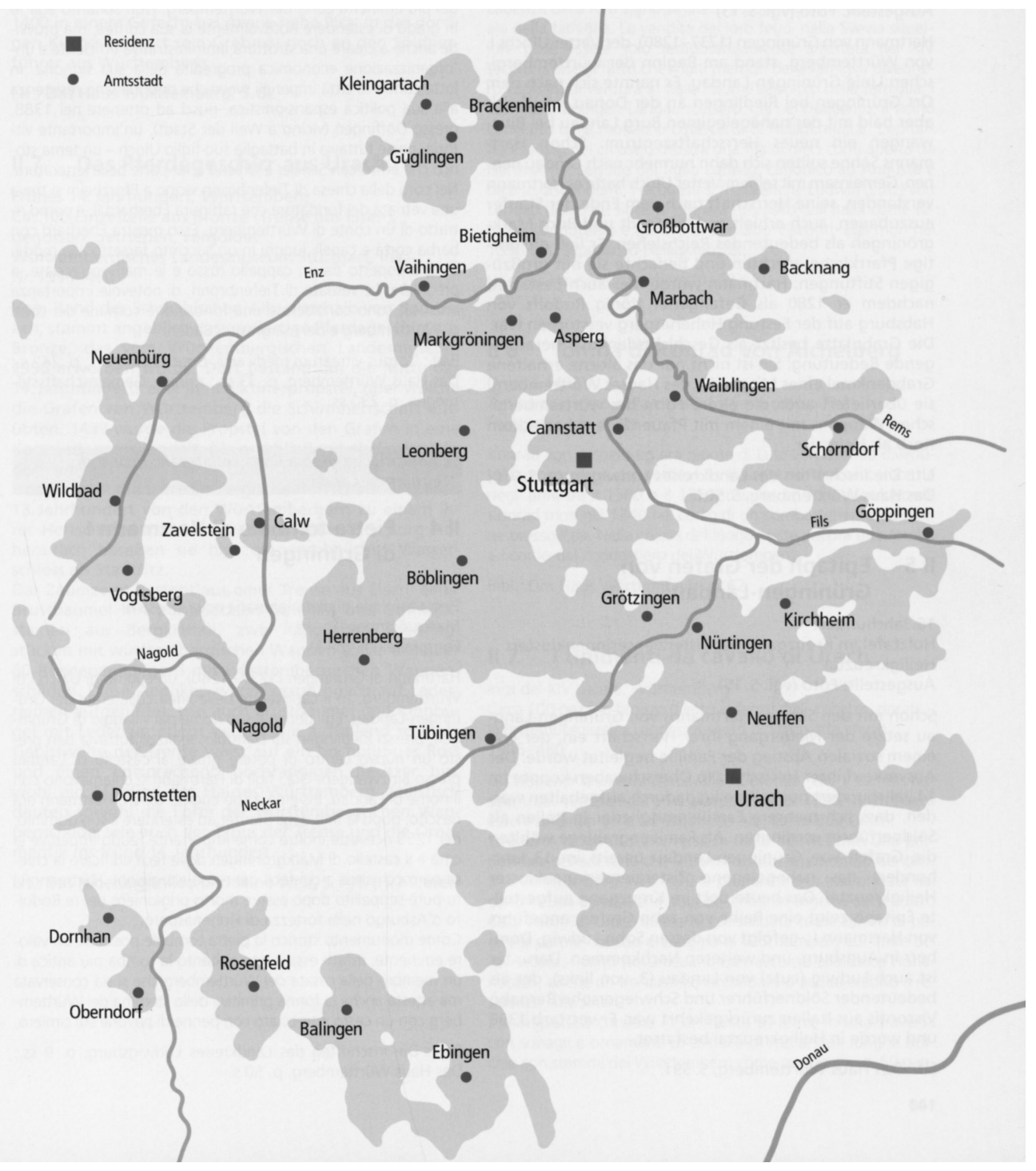

Abb. 10: Die Grafschaft Württemberg um 1400 (Entwurf: Peter Rückert, grafische Umsetzung: Katharina Schmid). 
wurden, den bürgerlichen Amtleuten, Kellern und Schultheißen auf dem Land ${ }^{81}$. Jetzt differenzierte sich die Amtsstruktur in der Zentralverwaltung weiter aus: Hof- und Landesangelegenheiten wurden bald vom Haus- bzw. Landhofmeister unterschiedlich wahrgenommen; letzterer blieb als oberster Amtsträger der Landesverwaltung Vorgesetzter der Vögte bzw. Amtmänner sowie oberste Finanzinstanz und maßgeblich an der Rechtsprechung beteiligt ${ }^{82}$.

Gleichzeitig werden (ab 1425) landesweit durchgeführte Steuererhebungen greifbar, welche die Ämterstruktur der Grafschaft auch in Hinblick auf die jeweilige Steuerkraft und Bevölkerungsstärke aufzeigen ${ }^{83}$ (Abb. 10). Um 1430 hatten die Vögte Zusammenstellungen der wehrhaften Mannschaft in ihren Ämtern anzufertigen, die weitgehend erhalten sind ${ }^{84}$ und aussagekräftige Zahlen bieten: Demnach hatten die Ämter Urach und Stuttgart deutlich am meisten Wehrfähige aufzustellen (1755 bzw. 1750 Mann), doch reichte die Skala der Ämter hinunter bis zu Wildbad und Vogtsberg mit unter 100 Wehrfähigen ${ }^{85}$. Größte Städte in der Grafschaft Württemberg waren demnach Tübingen und Stuttgart (mit 802 bzw. 749 Herdstätten/Häusern). Auch hier dehnt sich die Skala bis weit unter 100 Herdstätten/Häuser in den Amtsstädten Güglingen oder Rosenfeld aus. Mit diesen landesweiten Erhebungen werden nicht nur relative Vorstellungen von der zeitgenössischen Bevölkerungsverteilung vermittelt; sie stehen auch für eine neue Qualität der Landesverwaltung, die auf einem zunehmend ausdifferenzierten Schriftwesen basierte.

\section{Fazit und Ausblick}

Schließen wir damit den Kreis der Argumentation und runden ihn mit einem Ausblick ab: Als die beiden Grafenbrüder Ludwig und Ulrich zur Regierung kommen, teilen sie 1442 Württemberg „räumlich, rechnerisch und rechtlich neu und durchaus perfektionistisch“ in zwei Herrschaften auf, wie Dieter Mertens nachdrücklich formuliert hat ${ }^{86}$. Grundlage bildeten die 38 Ämter, deren gewachsenen Bestand und Umfang man unverändert ließ: die räumliche Verwaltungsorganisation war mittlerweile so voll entwickelt, dass ihre Struktur gleichsam das Territorium definierte. Die Amtsbezirke vereinten in sich sämtliche herrschaftlichen Rechte, d.h. Gerichts-, Wehr- und Steuerhoheit. Die Amtsstädte bildeten die Zentren der Amtsbezirke, in die die umliegenden Dörfer eingegliedert waren. Das städ-

\footnotetext{
81 Hammes (wie Anm. 77) S. 159.

82 Lorenz, Die Herrschaft (wie Anm. 4) S. 18.

83 Trugenberger, Der Erwerb (wie Anm. 59) S. $118 \mathrm{ff}$.

84 HStA Stuttgart A 602 Nr. 4326. Zur Neudatierung der entsprechenden Berichte durch die Wasserzeichen im Papier vgl. Trugenberger, Der Erwerb (wie Anm. 59) S. 120 ff.

85 Vgl. die Statistik (mit Grafik) bei Trugenberger, Der Erwerb (wie Anm. 59) S. 122.

86 Mertens, Württemberg (wie Anm.3) S. 49.
} 
tische Gericht hatte sich zum Hochgericht für das Amt entwickelt, ihre eigene Gerichtsbarkeit hatten die Städte dafür aufgegeben ${ }^{87}$.

Die überaus enge Verzahnung zwischen Stadt und Amt, zwischen städtischer und fürstlicher Verwaltung, städtischer und territorialer Elite, zwischen Land und Hof zeichnet die württembergische Herrschafts- und Verwaltungsstruktur bereits um die Mitte des 15. Jahrhunderts aus. Die zunehmende Besetzung der lokalen Ämter durch die amtsstädtische Oberschicht macht dabei auch eine Integration der bürgerlichen Eliten in die Landesherrschaft deutlich, die zeitgleich in keinem anderen Territorium so intensiv zu erkennen ist ${ }^{88}$. Sie ist vor allem auf die starke Einbindung der Städte in die fürstliche Herrschaft zurückzuführen. Ihre Vertreter, die württembergischen Amtleute, Richter und Bürger, identifizieren sich deutlich mit ihrer Herrschaft und ihrem Land und sind nun - in Zeiten der dynastischen Krise - auch in der Lage, dieses fordernd zu artikulieren: Die ersten württembergischen Landtage werde jetzt, 1457, in Stuttgart und Leonberg zusammengerufen. Was folgt, ist ein neues Kapitel politischer Partizipation, württembergischer Herrschafts- und Verwaltungsgeschichte ${ }^{89}$.

87 Hesse (wie Anm. 5) S. $123 \mathrm{f}$.

88 Ebd. S. 269. Vgl. dazu jetzt auch Kühnle (wie Anm. 58).

${ }^{89} \mathrm{Vgl}$. dazu den Forschungsstand in dem Sammelband: Auf dem Weg zur politischen Partizipation? (wie Anm. 4) und jetzt weiterführend Jonas Veit: „... mit rat, wissen und willen gemeiner landschaft ..." Über die „politische Partizipation“ der württembergischen Landstände. In: ZWLG 71 (2012) S. 129-168. 